\title{
Creating Culture Circles- A Case of Continuing Professional Development Workshop for Israeli Special Education Teachers
}

\author{
Roni Reingold $^{1 *}$, Keren Dery ${ }^{2}$ and Nira May ${ }^{1}$ \\ ${ }^{1}$ Achva Academic College, Israel \\ ${ }^{2}$ The Hebrew University of Jerusalem, Israel
}

\section{ARTICLE INFO}

\begin{tabular}{l}
\hline Keywords: \\
Teachers' Professional \\
Development \\
Critical Pedagogy \\
Culture Circle \\
Special Education \\
Teachers \\
Educational Philosophy
\end{tabular}

\begin{abstract}
The focus of critical educational philosophy is not only on criticising traditional education (Banking education), but also on promoting a pedagogy for liberation, whereby education is a cultural action for freedom. The main strategy or tool of critical pedagogy is the culture circle, a dialogical problem-posing method of education. The current qualitative case study examined the use of culture circles in a continuing professional development workshop for Israeli special education teachers. Given the over-representation of culturally and economically oppressed populations in the special education system, it would be appropriate to raise the awareness of the SE teachers of this situation. Findings revealed that while developing culture circles during the workshop, most of the teachers moved from proposing hurried and shallow solutions, to offering carefully thought-out ideas for joint analysis, following an in-depth review and definition of the problem. Despite starting the process with an idealised perception of society and an over-inflated sense of self-efficacy, when group participants completed the workshop, they had acquired the ability to acknowledge and even contend with the unjust conditions and imperfections of the Special Education System. It seems that, participating in culture circles can help teachers to both understand their current realty fully and deeply and to set meaningful goals for the future.
\end{abstract}

\section{Introduction}

Teachers are required to make an enormous amount of decisions and judgements in their everyday routine in the classroom. Special education teachers are required to make even more judgments, because they need to take the special and challenging needs of their pupils into consideration. Therefore, their pedagogical thinking is complicated and interactive, but it is oriented towards the individual student (Stough \& Palmer, 2003).

The Reflecting on their professional knowledge and choosing which strategies to use as pedagogical interventions is the essence of special-education teachers' work. Even when the declarative knowledge of the SE teachers about pupils and issues changes, the procedural knowledge stays stable: Teachers' responses to situations may be adapted to the individual student's needs, but the fundamental process of making pedagogical decisions does not change (Paul, French, \& Cranston-Gingras, 2001).

A social phenomenon that makes SE teachers' work become even more difficult is that many of the pupils who are placed in the special education system do not have any special needs. In Israel, despite the fact that an egalitarian rhetoric exists with relation to the special-needs education and the various movements towards inclusion, many of the pupils who are assigned to the special education system come from the population's lower socioeconomic classes or

* Corresponding Author E-Mail Address: reingold@achva.ac.il, reingold@netvision.net.il 
belong to ethnic groups that are deprived of political power (The Israel National Council for the Child, 2010). In other words, pupils from these groups are disproportionately overrepresented in the special education system.

This phenomenon is not unique to Israel. Many studies have consistently identified the disproportionate representation of minority students in special education classes in the US (Zhang, Katsiyannis, Ju, \& Roberts, 2014). Thus, for example, the percentage of Hispanic students who were diagnosed as having learning disabilities was significantly higher than the percentage of Caucasian children (Danforth, Taff, \& Ferguson, 2006). In special education schools and in inclusion classes in regular schools, African American students constitute the majority (Allan, 2008). Non-English-speaking immigrant pupils in regular schools were identified as lacking learning skills and abilities and, hence, they were assigned to special education schools (Danforth, et al. 2006). Given the over-representation of culturally and economically oppressed populations in the special education system, it would be appropriate to raise the awareness of the SE teachers of this situation. Adhering to their commitment to uphold professional moral standards, SE teachers would do well to remind the system (and the population) of special education's true role in society (Paul et al. 2001). Paulo Freire's critical pedagogy approach can serve as key tool for raising awareness.

\subsection{Theoretical Background}

Paulo Freire's political and educational philosophy deals not only with criticism of traditional education, which he referred to as 'the banking model of education' (Freire, 1970b), but it also seeks to develop principles of critical pedagogy, according to which education serves as a tool for liberation, that is, as a cultural act of emancipation (Shor \& Freire, 1987). Freire argued that change could come through a process of dialogue and reflection experienced by both the learner and the teacher and he insisted that this dialogue and problem-posing approach to education is renewed in every situation (Shor and Freire 1987). In this manner, the liberating pedagogy creates the conditions that make it possible to find a solution to any presented situation (Gadotti \& Torres, 2001).

Hence, a change must be introduced in teachers' guidelines and in teacher education. Freire wrote that teachers were excluded from decisions (Freire, 1993). The decision-makers are completely distant and removed from the teachers. The school curriculum is written and developed by clerks rather than by the teachers in the field (Freire, 1993). Thus, the teacher becomes yet another bureaucrat who perpetuates the existing social order.

Therefore, Freire believed that educating teachers is a crucial dimension for laying a solid and long-term foundation for the promotion of an educational practice that supports the development of critical citizenship among students. He complained about the technical nature of the training typically offered to teachers in the basic teacher-education programmes (Freire, 1993). Freire (1990) claimed that teachers' continuing professional development programmes must be based on practice-theory dialogues and deal with critical reflection on their practice. In his opinion, programmes should be conducted in groups that are based on investigating the local and contextual aspects of problems, in order to elucidate them (Freire, 1990).

Freire seeks the development of a teacher who is a researcher with a liberating authority. $\mathrm{He}$ claimed that the act of research does not come in addition to teaching, but rather is an inseparable part of the knowledge circle, which consists of learning and thinking about existing knowledge as well as producing new knowledge. He refers to learning, teaching, researching, experimenting, thinking, and communicating as ongoing and endless actions (Freire, 1998).

In the traditional learning process (the banking model of education), knowledge is produced without involving the students and is presented to them for revising and memorising. The students (or student teachers in teacher-education programmes) receive the knowledge 
through a kind of intellectual funnel; they passively receive known knowledge. In contrast, in appropriate teaching and learning methods, two conditions of learning coexist in the form of a dialogue: The knowledge production stage, in which new knowledge is formed, and the awareness to the conceived knowledge stage, which refers to when the pupils (either young or old) see the knowledge as their own (Shor \& Freire, 1987).

This dialogical process of gaining knowledge is best practised in a group-learning method, known by Freire as the culture circle (Freire, 1970a; Chaib, 2010; Hickling-Hudson, 2014, Stromquist, 2014). In the course of a culture circle, participants 'practice a collective, dialogic exchange of reflections. This collective learning takes the form of praxis - the cycle of conscientisation' (Hickling-Hudson, 2014, 525). To elaborate, 'through dialogue, the participants and the coordinator of the cultural circle together would either clarify situations or seek action arising from that clarification' (Williams, 2009, 4).

Freire led the culture circles approach in Brazil in the 1950s and 1960s, as a practice of teaching illiterate people (Chaib, 2010). When the first massive culture circle, which took place with 300 sugarcane workers in February/March 1963 became a success (Stromquist, 2014), the Brazilian government allowed '20,000 culture circles throughout Brazil, aimed at serving two million adults' (p.550).

Culture circles became increasingly known also beyond the borders of Brazil, and were conducted in numerous societies (Chaib, 2010; Souto-Manning, 2010), in many cases, with the guidance of educators. One of the most well-known successful culture circles took place in on the Caribbean island of Grenada in 1980, a year after the end of a democratic revolution (Hickling-Hudson, 2014). It is important to note that Freire, who conceptualised the culture circle in his dissertation (which afterwards was published: Freire, 1970a), did not present any explicit model to illuminate the aspect of praxis; rather, he believed that each educational act should be unique (Freire, 1993; Shor \& Freire 1987). He further argued that change could come through a process of dialogue and reflection practised by both the learner and the teacher. Hence, he insisted that this dialogue and problem-posing educational process (Shor 7 Freire, 1987) is defined anew each time it is practised. Accordingly, the instructor of the workshop developed her own five-stage model, by which to conduct and manage the dialogue. The stages are described herein.

- Stage 1: Presenting a problem to solve. The participants present a topic, problem, situation, conflict or dilemma. In order to enable the group to present a problem for discussion, a climate of trust must be created.

- Stage 2: Defining the problem. The problem is elucidated through the responses it evokes from the participants. Together they examine the concerns that it stimulates. In this manner they clarify their knowledge of dealing with different aspects of the problem.

- Stage 3: Problem analysis. The participants are requested to examine the problem from different angles and to address concrete aspects of the problem by answering questions such as these: What are the hidden interests of the people involved? Who is negatively affected by it? What are the ethical aspects evoked by the situation?

- Stage 4: Solution proposals. The participants should propose, examine, and raise doubts about the familiar, standard, and acceptable solutions. Following, a search and examination of new solutions is carried out by the participants.

- Stage 5: Process analysis. In this final stage, the participants are requested to review their previous knowledge and the kind of solutions they had encountered before participating in the culture circles. What were the sources of knowledge that guided the participants during the workshop? What new knowledge did the participants gain? This last question highlights the advantages of using the group as a source of knowledge and 
the richness of this process, for analysing problems, finding solutions, and benefitting from mutual assistance and support offered by the workshop participants.

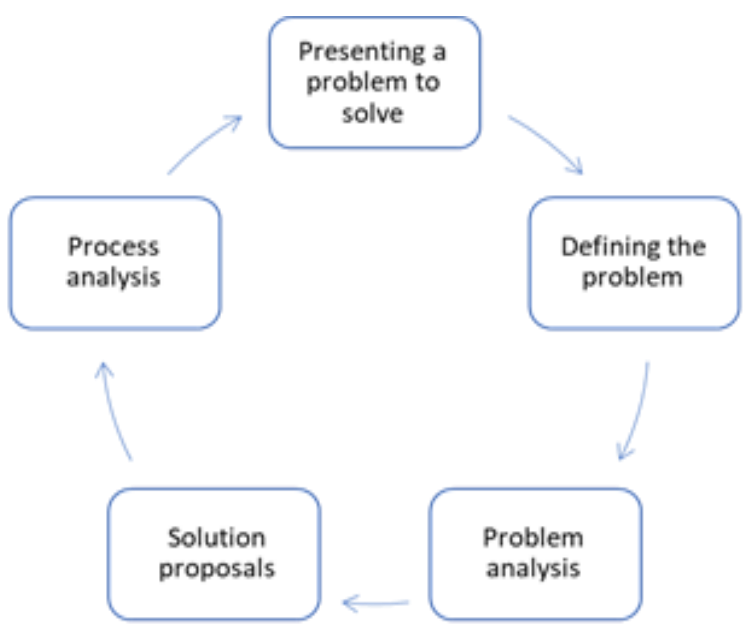

Figure 1. The stages of the dialogue process

In each session, the dialogue process started from the beginning: with a problem raised and until the process was analyzed. In this way, workshop participants have repeatedly experienced the process of creating knowledge.

The model described offers a systematic discourse. Pereira characterized the teacher as a person, who feels he or she has new knowledge to contribute to her students. Knowledge that may help them develop critical thinking and see their worlds differently. Dialogic teaching does not abolish the hierarchy between learner and teacher, but to give in a humane way.

First, the teacher learns about the world of learners, from which she understands how she can contribute to them. Later, in dialogue, she finds out how they see the new knowledge he or she imparts to them. From this, the teacher also learns about the knowledge she imparts. The less the dominance of the teacher (instructor), the more workshop participants are able to manage the cultural circles themselves.

The workshop is anchored in the concept of lifelong learning, which relates to the multiple facets of a teacher's personal, social, civic, and professional identity (Collinson et al. 2009). Good teachers are those who engage in lifelong learning, not only in relation to their role as teachers, but also as intellectually curious people and as active members of their communities and societies. Likewise, in their teaching approach, they treat students as lifelong learners (Berliner, 2001; Guskey \& Yoon, 2009). A study, that examined several models of teachers' professional development in the United States, argue that communities of practice offer the most promising lens for sustained growth and change (Crafton \& Kaiser, 2011).

Professional development, based on Coacher, which serves as an expert, sets the tone for professional development and limits the voices of teachers. On the other hand, professional development based on cooperation and dialogue influences students within the group and at the same time shapes their identity. The influence of a dialogue community extends beyond the boundaries of the workshop. The conversations continue in the teachers' room, in the mail, in the hallway conversations, etc. (Crafton \& Kaiser, 2011).

\section{Materials and Methods}

An explanatory qualitative case study (Baxter \& Jack, 2008) was conducted, in order to explain the use of cultural circles as the framework in a workshop for the ongoing professional development of SE teachers. This research approach allowed for a detailed observation of the developments in the process of defining and solving the problems of SE teachers. 
Acknowledging that some teachers may experience a pattern or occasional misunderstandings as they conceptualise problems and seek proper solutions, the principal of a school for children with special needs invited the researchers to design and lead an action research. Although this seems to cast it as a technical action research (Grundy, 1982), findings are expected to eventually reveal that it in fact served the purpose of an emancipatory action research (Ledwith, 2007).

The participants in the current research were twelve SE staff members, including the counsellor and the principal of the school, all of whom had the role of educators in this small SE school. The teachers' experience in the field ranged from two to thirty-three years of teaching (mean --13.1 years, median --10 years).

The workshop consisted of six sessions --, all of them were video recorded. The role of one of the researchers was to conduct the workshop sessions, whereas the other researchers observed and analysed the recorded sessions. By recording the sessions, it was possible to review the footage for retrospective processing. This protocol enabled a more detailed analysis and reduced the possibility of premature deduction not based on enough interpretation (Ratcliffe, 2003). Another advantage of the recordings was the preservation of the dimension of movement in time, which made it possible to identify patterns, processes, and sometimes even cause-and-effect situations (Ratcliffe, 2003).

The participants' input consisted of a qualitative, 'self-defined narrative', in which each participant described a specific incident in his or her life story (Spector-Mersel, 2011), which served to demonstrate a problem-solving process. Given that the data collected in the study was of a narrative nature, the analysis was based on the principles of narrative analysis, as defined by Miles and Huberman (1994).

\section{Results}

Each session was about one hour long. At most, this time was enough to complete all the stages of only one problem. In 50\% of the sessions, the problem was not proposed by the instructor, but rather by one of the participants. Notwithstanding, the workshop's instructor was always active in helping participants conceptualise the problem. In fact, the instructor's partial participation and the type of content she contributes provide an important indication of the participants' understanding of the process of preparing and conducting culture circles.

Considering the total discussion time as the whole, the instructor's rate of participation in each session was noted, as was the teachers' rate of participation, which varied greatly among participants and from one session to the next. The data indicated a general tendency of decreased instructor participation (almost constant and routine) from one session to the next.

- First session- 49.6\%, 11 discussions, 63 responses.

- Second session- 34.5\%, 4 discussion threads, 56 responses.

- Third session- $21.5 \%, 9$ discussion threads, 56 responses.

- Fourth session- 34.5\%, 12 discussion threads, 54 responses.

- Fifth session- 10\%, 3 discussion threads, 42 responses.

- Sixth session- 25\%, 8 discussion threads, 31 responses.

The quotations in Table 1 (Appendix A) are key citations, which divided into the systematic structure of the workshop: Presenting a problem to solve, defining the problem, analysing the problems, presenting the solutions, as well as process analysis (reflection). we can see the progress of the group in developing its ability to conduct a systematic critical dialogue. All quotations are saying of the workshops' participating teachers, except as stated by the instructor.

Followed is a description of the six sessions. 


\subsection{The first session}

During the first session, there were voices of antagonism to new ideas and to different ways of thinking. These voices continued, starting from the stage of defining the problem all the way to the stage of solution proposals. When the instructor proposed a solution, the group opposed. The opening session raised a feeling of great professional self-efficacy (perhaps exaggeratedly so) when discussing possible solutions to school problems, and the group displayed an active and cooperative dynamic. It was as though there were a group narrative that said: 'we are a strong, homogenous, cohesive family that provides for each other'.

None of the teachers were opposed to the profound cooperation that helps to deal extensively with a problem. They expressed an almost completely united front by the end of the first session, as they described their lack of interest or willingness to continue with the workshop. This kind of antagonism was predictable; in our opinion, it was related to several reasons. Their job is stressful; they have to take part in many meetings which they consider unnecessary; they are often required to take courses that they view as unnecessary; and it is a well-known fact that they do not get adequately remunerated. It is safe to assume that defining this as a reflective workshop contributed to the antagonism. However, as a result of the school-principal's insistence and the decision to hold this workshop during the daily work hours at time slots that were initially intended for scheduled meetings, the teachers agreed to cooperate and to continue attending the workshop. Most of the teachers took part in all the sessions.

The teachers' antagonism was stronger in the stage of the proposing solutions than at the stage of the analysis; this is understandable, given the fact that once a solution is accepted, their involvement and cooperation are required. When the instructor introduced critical ideas, these were perceived as the attempt of an academician from outside the education system to impose a solution, rather than as a proposal to be examined and analysed. The instructor suggested that their antagonism stems from their frustration at having little or no influence on either the educational or the social system. Conducting the pedagogical dialogue in this manner laid the foundation for critical thinking.

\subsection{The second session}

In this session we can already see the development of the group. Now, at the point of analyzing the problem, the participants ask piercing questions about the limits of their job and raise thoughts that undermine the order they have become accustomed to. Which reflects the development of critical learning? The participants express disagreement with the current situation, confronting ideas that they considered legitimate until now. The analysis phase of the problem was really critical.

Still, at the stage of proposing the solution and in the reflection stage, the participants clung to the known and familiar solutions. some of the teachers tried to present a purposeful approach and use efficacy and output terms. The common assumption was that solutions are instant and require resources.

Some of the teachers even turned to the instructor for possible solutions. Many of the proposed solutions were grasped as utopian and unrealistic.

They did not question these solutions and it was clear that they had not thought of thinking about other solutions. Most of the teachers lacked the internal conviction to provide time to think and deliberate.

However, we believe that the sense of freedom to enter into an internal and group conflict with the existing situation, to flood conflicts on the surface, even if conflicts have not yet been resolved, expresses progress in the Freerian learning stages. 


\subsection{The third session}

The problem discussed in the third session, was suggested by the instructor, who thought the group was moving forward and ready to deal with it. The instructor asked the participants (knowing that they cannot change the population structure) to try to define the problem by imagining a hypothetical or utopian solution, and suggesting methods which in their minds would constitute an ideal way to manage the class:" An option that can help us get to defining the problem is to think about a hypothetical solution. Think of what a class looks like when you're in it, dealing with diversity".

At the stage of defining the problem, the instructor encountered highly emotional responses.

Furthermore, some participants expressed a great deal of resentment and antagonism at being asked to imagine an ideal state. The teachers conveyed their underlying conformist desire to adhere to their familiar patterns and approach; every so often, however, they could not contain their frustration at having to deal with the change.

The teachers clearly shared the perspective that something was amiss, rather than viewing this as a change that requires them to adapt professionally. Despite the fact that, objectively, the student population had changed substantially, the teachers' educational approach had not shifted in the least.

There were many difficulties when trying to define solutions during the third session. Despite the disgruntlement and pain this topic aroused, once the emotional and antagonistic tenor of responses subsided, many of the participants presented an alternative view of school.

In all, the participants' proposals reflected their vision that in SE, teaching is the main essence of their role, whereas the paramedical staff and therapy classes in school were perceived as responsible for caregiving. Thus, the participants conveyed a preference for the conservative approach.

In the process of conceptualizing the problem, the teachers were clearly clinging to what they perceived as familiar, correct, and acceptable. The teachers did not seem to have confidence in their ability to affect reality. They demonstrated no sense of degrees of freedom, as in the ability to change their attitude, shift the goals of the curriculum, or adjust their pedagogical didactic methods to the given reality. Their need to conform to what they considered normal was stronger than their need to exercise choice. It appeared that they had very much internalized the traditional role of teachers.

\subsection{The fourth session}

The problem that was dealt with in the fourth session was proposed by one of the teachers. This teacher was preoccupied with the fact that some pupils did not succeed with reading acquisition. The deliberation at hand focused on the extent to which one must insist on reading acquisition with such pupils.

The teacher described both the difficulties of the pupils and exertion of the teacher, thus demonstrating that she had acquired the ability to conceptualize a problem.

By the fourth session, the teachers felt more secure about expressing what they had to say during the conceptualization of the problem. In fact, all teachers, including those who had refrained from taking part in previous sessions, contributed significantly to the discussion. Moreover, as the discussion developed, participants veered on to nonconventional areas.

During the conceptualizing process, the teachers allowed themselves to receive credit for their pupils' achievements, for instance, in reading. The success of a pupil is grasped as the teacher's success.

Teachers experienced, during the fourth session, a breakthrough in the process of analyzing the proposed problem. However, it seemed that there was no progress in the process of finding solutions. One of the less active participants chose to defend the institutional policy. 
She persisted with the formal attitude. She spoke about her beliefs in terms of measurable achievements.

One participant raised an interesting, process-related question.

After the instructor reminded the participants of the stages of the process, a change was noted in some of the participants' attitudes towards the process analysis, as they seemed encouraged and accepted responsibility for their beliefs and for their pedagogical and social ideology. They began to express this ideology to the group.

\subsection{The fifth session}

In this session, the instructor presented a question about the reasons for choosing to be a teacher in special education, and the discussion revolves around her question, and developed into a discussion around more questions

The purpose of this session was to reconsider how participants view their professional world. Has there been a change? And, following the process they have undergone, have developed critical awareness and have changed their minds? What do they think of special education now? What does special education mean to them now, one session before the end of the workshop? This is not a feedback conversation about the workshop, but a continuation of a clearly characterized, ongoing dialogue.

\subsection{The sixth session}

The sixth and last session was completely dedicated to discussing the differences between workshops based on Freire's cultural circles as compared to workshops based on conventional methods. Most of the participants confirmed that the workshop process was significant; that sometimes it caused pleasure, sometimes pain; and that it empowered them and the teamwork. Nevertheless, some of the participants reported that they were disappointed in the professional development of the workshop.

These quotes indicate that there is widespread belief that learning is something that is done under pressure and is not straightforward, and that an innovation is supposed to come from the outside. Nonetheless, some of the group members were able to see the type of knowledge that the group obtained.

\section{Discussion}

The current paper presented the finding of a pilot action research that examined the possible outcomes of applying the culture circle approach among experienced teachers in an Israeli SE school. The findings do not suggest the suitability of the culture circles to every educational situation. As Freire suggested, every pedagogical situation is unique (Shor \& Freire, 1987).

The findings indicate that culture circles indeed can be useful in an educational process that aspires to develop a critical professional attitude to educational problems. Prior to the workshop, most of the participants had a strong sense of self-efficacy and consequently the felt certain that they did not stand to benefit from the workshop. This sense turned out to be exaggerated. At the beginning of the workshop process, the participants found it to define the problems that they were dealing with. They did not fully understand the different causes of these problems and did not have the capability to think 'outside the box' for solutions in a clear and a critical way. Finally, they managed to overcome these difficulties and successfully learned how to define, analyse, and propose solutions using a critical way of thinking. Their exaggerated sense of self-efficacy, in conjunction with their workload and a lack of awareness of complex situations can serve as obstacles, which SE teachers frequently encounter and which they need to overcome.

At first, the participants showed either an active or a passive attitude towards participating in the workshop. They did not propose too many problems or solutions, and were greatly 
dependent on the workshop's instructor. As the workshop progressed, most of these characteristics were changed among many of the participants.

Professional development is evaluated in terms of the teacher's abilities, knowledge and professional skills, which lead to professional achievements in one's area of expertise (Sheldon \& Clark, 2012). According to Berliner (2001), teachers in the course of their professional development are expected not only to accumulate knowledge, but also to use this knowledge to influence the organisational culture. Hence, these teachers' lifelong learning experiences can be upgraded with the use of culture circle workshops, as part of teachers' continuing professional development. The point of departure in the process of teachers' professional development is their current stage; from there, they evolve towards whatever professional goals they set for themselves (Opfer, Pedder, \& Lavciza -check spelling, 2011). Participating in culture circles can help teachers to both understand their current realty fully and deeply and to set meaningful goals for the future.

\section{References}

Allan, J. (2008). Rethinking inclusive education: The philosophers of difference in practice. Dordecht, Netherlands: Springer.

Baxter, P. \& Jack, S. (2008). Qualitative case study methodology: Study design and implementation for novice researchers, The Qualitative Report, 13(4), 544-559.

Berliner, D. C. (2001). Learning about and learning from expert teachers. International Journal of Educational Research, 35 (5), 463-483.

Chaib, D. (2010). Music listening circles: Contributions from development education to democratising classical music developments, Policy and Practice: A Development Education Review, 10, 42-58.

Collinson, V., Kozina, E., Kate Lin, Y. H., Ling, L., Matheson, I., Newcombe, L. \& Zogla, I. (2009). Professional development for teachers: A world of change. European Journal of Teacher Education, 32(1), 3-19.

Crafton, L., \& Kaiser, E. (2011). The language of collaboration: Dialogue and identity in teacher professional development. Improving Schools, 14(2), 104-116.

Danforth, S., Taff, S., \& Ferguson, P. (2006). Place, profession, and program in the history of special education curriculum. In E. Brantlinger (Ed.), Who benefits from special education? Remediating (fixing) other people's children (pp. 1-25). New York: Routledge

Freire, P. (1970a). Cultural Action for Freedom. Harvard Educational Review and Center for the Study of Development and Social Change: Cambridge, Massachusetts.

Freire, P. (1970b). Pedagogia del Oprimido. Siglo XXI de Espania editores s.a.Mexico, Espania.

Freire, P. (1990). La Naturaleza Política de la Educación, Cultura, Poder y Liberación, tr. Horvath, S. Ediciones Paidos, Barcelona, Buenos Aires, Mexico.

Freire, P. (1993). Cartas a quien pretende ensenar. Siglo XXI Editores: Mexico.

Freire, P. (1998). Pedagogia de la autonomía (trans,. G. Palacios). Siglo XXI Editores, Mexico.

Gadotti, M. \& Torres, C.A. (2001). Paulo Freire: Una biobibliografía. Siglo XXI Editores: Mexico. 
Guskey, T. \& Yoom, K. (2009). What works in professional development? Phi Delta Kappan, 90(7), 495-500.

Grundy, S. (1982). Three modes of action research, Curriculum Perspective, 2, (3), 23-34.

Hickling - Hudson, A. (2014). Striving for a better world: Lessons from Freire in Grenada, Jamaica and Australia, International Review of Education, 60 (4), 523-543.

Miles, M. B., \& Huberman, A. M. (1994). Qualitative data analysis (2nd ed.). Thousand Oaks, CA: Sage.

Ledwith, M. (2007). On Being Critical: Uniting Theory and Practice through Emancipatory Action Research, Educational Action Research, 15 (4), 597-611.

Miles, M. B. \& Huberman, A. M. (1994). Qualitative Data Analysis 2nd edition. Newbury Park, CA: Sage.

Opfer, V. D., Pedder, D. G. \& Lavciza -check spelling, Z. (2011). The role of teachers' orientation to learning in professional development and change: A national study of teachers in England. Teaching and Teacher Education, 27 (2), 443-453.

Paul, J., French, P. \& Cranston-Gingras, A. (2001). Ethics and special education: Focus on exceptional children. Denver, 34(1), $1-16$.

Ratcliff, D. (2003). Video methods in qualitative research. In P. M. Camic, J. E. Rhodes and L. Yardley (Eds.), Qualitative research in psychology: Expanding perspectives in methodology and design, (pp. 113-129). Washington, DC: American Psychological Association.

Sheldon, B. \& Clark, M. C. (2012). In pursuit of excellence in teaching: An ESL educator's narrative. Journal of Educational Change, 13 (1), 41-66.

Shor, I. \& Freire, P. (1987). A pedagogy for liberation. Westport, CT: Greenwood.

Souto-Manning, M. (2010). Freire, Teaching, and Learning: Culture Circles Across Contexts. New York: Peter Lang.

Spector-Mersel, G. (2011). Mechanisms of selection in claiming narrative identities: A model for interpreting narratives. Qualitative Inquiry, 17(2), 172-185.

Stough, L.M. \& Palmer, D.J. (2003). Special thinking in special settings: A qualitative study of expert special educators. The Journal of Special Education, 36(4), 206 - 222.

Stromquist, N. P. (2014). Freire, literacy and emancipatory gender learning, International Review of Education, 60, 545-558.

The Israel National Council for the Child (2010). Analysis of data from the Israeli Ministry of Education and the Central Bureau of Statistics (in Hebrew).

Williams, D. (2009). The Critical Cultural Cypher: Remaking Paulo Freire's Cultural Circles Using Hip Hop Culture, International Journal of Critical Pedagogy, 2 (1), 1-29.

Zhang, D., Katsiyannis, A., Ju, S., \& Roberts, E. (2014). Minority representation in special education: 5-year trends. Journal of Child Family Studies, 23, 118-127. 


\section{Appendix A}

Table 1. Process of Development of Critical Discourse in a Culture Circle

\begin{tabular}{|c|c|c|c|c|c|}
\hline & problem to solve & Defining the problem & Problem analysis & Solution proposals & Process analysis \\
\hline First session & $\begin{array}{l}\text { " The problem I want to present is a } \\
\text { dilemma about the dropout of students } \\
\text { after the age of } 17 \text {. These students are not } \\
\text { interested in getting to school, they do not } \\
\text { have to go to school and no one can do } \\
\text { anything about it. This is an embarrassing } \\
\text { and very bad situation. The street interests } \\
\text { them a lot more than the studies, and they } \\
\text { know by law that they have to go to school } \\
\text { by grade nine, no more than that, they do } \\
\text { not have to. The dropout rate is high, } \\
\text { although in special education they are } \\
\text { entitled, if they are interested, to stay until } \\
\text { they reach the age of } 21 " .\end{array}$ & $\begin{array}{l}\text { "I assume that the problem is } \\
\text { also related to the lack of } \\
\text { cooperation of the parents. } \\
\text { The teachers give up and feel } \\
\text { that there is no solution to } \\
\text { offer that can prevent the } \\
\text { students from dropping out" }\end{array}$ & $\begin{array}{l}\text { "The problem stems from the absence of a } \\
\text { curriculum suitable for the age of the children who } \\
\text { drop out" } \\
\text { "the large institutional bodies are less interested in } \\
\text { those young people deprived of the poor" } \\
\text { "the system is not really interested in finding real } \\
\text { solutions. It also includes the community, not just } \\
\text { the political institutions. Then it is clear that the } \\
\text { students and the parents will feel deprived" } \\
\text { "Welfare services have a lot to do, and not provide } \\
\text { a solution for all consumers." } \\
\text { The workshop's instructor: 'it is substantial that } \\
\text { they have trouble dealing and listening to the } \\
\text { critical point of view. They completely oppose to it } \\
\text { because it hurts them. This places them, as } \\
\text { professionals, at the bottom of the constitutional } \\
\text { hierarchy. Even though some of the teachers try to } \\
\text { defend the constitution and its factors'. }\end{array}$ & $\begin{array}{l}\text { "This has been tried. We } \\
\text { have done that. There is } \\
\text { nothing we haven't tried. } \\
\text { We have tried everything" } \\
\text { "I hate to say that this } \\
\text { solution had already been } \\
\text { tried, because we are } \\
\text { supposed to be opened } \\
\text { minded" }\end{array}$ & $\begin{array}{l}\text { 'We sit and talk with each } \\
\text { other. The session did not } \\
\text { help much' } \\
\text { 'When I have a problem, I } \\
\text { turn to my friends, } \\
\text { colleagues with whom I } \\
\text { have been working for } \\
\text { many years, and I ask them } \\
\text { what they think I should do } \\
\text {--just like what we did here } \\
\text { today' }\end{array}$ \\
\hline Second session & $\begin{array}{l}\text { "My student's parents are always } \\
\text { disappointed with the grades she is getting, } \\
\text { complaining and angry when they discover } \\
\text { that the student has received low grades, } \\
\text { and even write angry letters. Although } \\
\text { every time I tried to come up with possible } \\
\text { solutions that could advance the child, her } \\
\text { parents objected to my solutions. } \\
\text { Parental intervention prevents me from } \\
\text { helping my student. Their intervention } \\
\text { reduces the child's confidence in her } \\
\text { abilities and also limits my ability to help } \\
\text { her." }\end{array}$ & $\begin{array}{l}\text { How many times can you } \\
\text { talk with parents and still } \\
\text { nothing helps? Our job is to } \\
\text { help the child make progress. } \\
\text { We, as educators are not able } \\
\text { to help the parents; we can } \\
\text { only strengthen the child' }\end{array}$ & $\begin{array}{l}\text { "The mother causes the child an injustice, she } \\
\text { harms her by intervening and casting doubt on } \\
\text { you"/ } \\
\text { " Parents are responsible for what is happening, } \\
\text { their actions towards the girl make things worse"/ } \\
\text { 'does the teacher's responsibility include dealing } \\
\text { with and getting involved in the personal problems } \\
\text { of pupils' parents?'/ } \\
\text { " Our profession includes self-sacrifice, we are in } \\
\text { situations of this kind and we have to deal with } \\
\text { them almost every day in one form or another"/ } \\
\text { " We can not always bring all the solutions, we are } \\
\text { limited because of the nature of the profession" }\end{array}$ & $\begin{array}{l}\text { "Well? Have you thought } \\
\text { of something?" }\end{array}$ & See session description \\
\hline Third session & $\begin{array}{l}\text { Proposal by the instructor: the structure of } \\
\text { the pupil population since the changes in } \\
\text { Israeli law about inclusion in schools, } \\
\text { Makes difficulties distribute the pupils in } \\
\text { homogeneous groups in classrooms. }\end{array}$ & $\begin{array}{l}\text { 'It is hard to describe the } \\
\text { difficulties in words, because } \\
\text { it hurts' } \\
\text { 'I never let myself think of } \\
\text { something that is remote' } \\
\text { 'it does not empower me; on } \\
\text { the contrary, it causes me } \\
\text { more concern' }\end{array}$ & $\begin{array}{l}\text { "All day long we are concerned with providing care } \\
\text { and treatment... [As a result], our role is now } \\
\text { completely different'; 'this type of child creates a } \\
\text { sense of unease'; 'beforehand, the common } \\
\text { denominator was academic - there was an } \\
\text { academic core and students make progress } \\
\text { academically, [which gave us] a sense of } \\
\text { fulfilment'; 'all day I'm busy putting out fires, and } \\
\text { that's not something I trained for professionally'; } \\
\text { "when I get home, I think to myself, "what have I } \\
\text { done today?!" }\end{array}$ & $\begin{array}{l}\text { "The ideal would be to } \\
\text { have an educational staff } \\
\text { that would [be available to] } \\
\text { take care of the children } \\
\text { when needed. Then, we } \\
\text { would be able to continue } \\
\text { with our mission, which is } \\
\text { to teach. This is how I } \\
\text { would like the world to be" } \\
\text { 'classes with fewer pupils } \\
\text { and a homogeneous } \\
\text { classroom'; 'It is important } \\
\text { to state that the SE classes } \\
\text { contain relatively few }\end{array}$ & $\begin{array}{l}\text { 'The school must cope with } \\
\text { children who do not match } \\
\text { the level of the majority of } \\
\text { students and that's how it's } \\
\text { going to be'; 'I prepare for } \\
\text { lessons as I do every day... } \\
\text { If they [the students] are } \\
\text { calm, then I can start the } \\
\text { morning as planned'; 'we } \\
\text { come here in order to } \\
\text { teach... We prepare special } \\
\text { lesson plans, so that the rest } \\
\text { of the students can continue } \\
\text { studying as usual' }\end{array}$ \\
\hline
\end{tabular}




\begin{tabular}{|c|c|c|c|c|c|}
\hline & & & & $\begin{array}{l}\text { pupils, but are very } \\
\text { heterogeneous'; } \\
\text { " There is intensive work } \\
\text { being done on the } \\
\text { individual level, with } \\
\text { special classes offered } \\
\text { throughout the day'. } \\
\text { Another participant's ideal } \\
\text { was to 'make the school an } \\
\text { open school'. }\end{array}$ & \\
\hline Fourth session & $\begin{array}{l}\text { " Some of my students have not yet } \\
\text { acquired the ability to read properly. The } \\
\text { thought that comes to my mind is whether } \\
\text { we, as teachers of special education, } \\
\text { should insist, not give up on imparting the } \\
\text { ability to read?" }\end{array}$ & $\begin{array}{l}\text { 'I feel that I'm defining the } \\
\text { pupil's future' }\end{array}$ & See session description & 'I have a solution for you'. & $\begin{array}{l}\text { " given that we were the } \\
\text { ones to conceptualise and } \\
\text { define the problem, should } \\
\text { we consider ourselves } \\
\text { capable of judging } \\
\text { objectively whether our } \\
\text { proposed solutions are } \\
\text { viable?" }\end{array}$ \\
\hline Fifth session & \multicolumn{2}{|c|}{$\begin{array}{l}\text { the instructor raised the following questions: What made you study special } \\
\text { education? When and how did you decide? } \\
\text { During the session, the participants reformulated the issues as: What are the } \\
\text { aspects of the job that generate satisfaction and prevent exhaustion? }\end{array}$} & \multicolumn{3}{|c|}{$\begin{array}{l}\text { 'I was always motivated to help others: if someone is weak and needs help, I feel I have to give my support'; 'part } \\
\text { of the job is holy and sacred - in a one-on-one format, it is a blessing to see how much can be achieved'; 'The } \\
\text { children here are more innocent and they give love and warmth in return'; 'I found something in this job that } \\
\text { meets my personal needs'; 'The perception that links between teaching-learning and success is conserved. Being at } \\
\text { a SE school is a developing experience which provides a source of happiness and significance'. }\end{array}$} \\
\hline Sixth session & \multicolumn{2}{|c|}{$\begin{array}{l}\text { The participants were asked about their perceptions about the workshops' } \\
\text { contribution to their ability to define and solve problems }\end{array}$} & \multicolumn{3}{|c|}{$\begin{array}{l}\text { "There were insights.. Many times I felt frustrated "because things that were raised seemed not to have a solution... } \\
\text { now there is a sense of calmness and acceptance... In addition, there was an increasing sense of unity and } \\
\text { consolidation in the group". } \\
\text { " When you state your opinion, it empowers you. It strengthens your thinking, especially when it generates a } \\
\text { consensus. It enhances the rationale that stands behind it... It's something that you share and distribute rather than } \\
\text { keeping it to yourself'/ } \\
\text { 'The workshop reflects reality. There were sessions where I said that we should take what was discussed and } \\
\text { follow it through... it's our real voice'/ } \\
\text { "None of what we learned was presented to us from an 'outside' party... in any given session we did not know } \\
\text { what subject we would end up talking about. We have received and gained new self-knowledge. Here each } \\
\text { participant contributes to the production of the knowledge"/ } \\
\text { "I found it very helpful to learn about the different opinions that my friends have... I learned that I can learn a lo } \\
\text { from my staff members and that I don't need to look for the knowledge just from external sources"/ } \\
\text { 'there was no learning process; just conversations'; 'usually a professional development programme has a specific } \\
\text { topic and this one didn't' 'teacher-room conversations, [like] a friendly dialogue that focused on a certain subject'; } \\
\text { 'There wasn't anvthing concrete that can [be used to] facilitate our iob' }\end{array}$} \\
\hline
\end{tabular}

